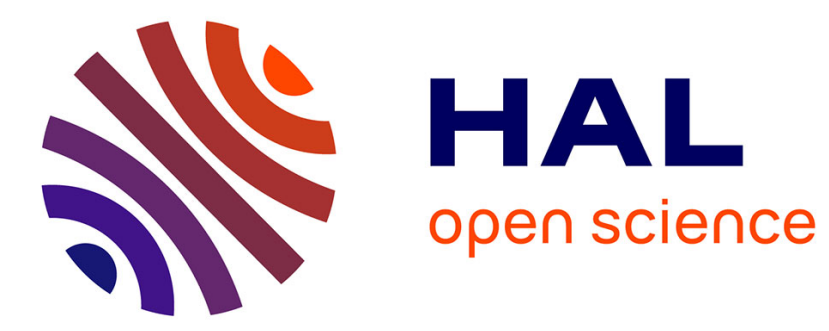

\title{
Ab initio study of MgH2: Destabilizing effects of selective substitutions by transition metals
}

\author{
Adel F. Al Alam, Samir F. Matar, Naïm Ouaïni
}

\section{To cite this version:}

Adel F. Al Alam, Samir F. Matar, Naïm Ouaïni. Ab initio study of MgH2: Destabilizing effects of selective substitutions by transition metals. Solid State Sciences, 2014, 36, pp.47-51. 10.1016/j.solidstatesciences.2014.07.010 . hal-01060378

\section{HAL Id: hal-01060378 https://hal.science/hal-01060378}

Submitted on 3 Sep 2014

HAL is a multi-disciplinary open access archive for the deposit and dissemination of scientific research documents, whether they are published or not. The documents may come from teaching and research institutions in France or abroad, or from public or private research centers.
L'archive ouverte pluridisciplinaire HAL, est destinée au dépôt et à la diffusion de documents scientifiques de niveau recherche, publiés ou non, émanant des établissements d'enseignement et de recherche français ou étrangers, des laboratoires publics ou privés. 
Solid State Sciences; accepted July 22nd 2014

\section{$A b$ initio study of $\mathrm{MgH}_{2}$ : destabilizing effects of selective substitutions by transition metals.}

Adel F. Al Alam a,b*, Samir F. Matarc,d, Naïm Ouainia.

a Holy Spirit University of Kaslik, USEK, P.O. Box 446, Jounieh, Lebanon

b University of Balamand, Department of Physics, P.O. Box 100, Tripoli, Lebanon

c CNRS, ICMCB, UPR 9048, F-33600 Pessac, France

d Université de Bordeaux, ICMCB, UPR 9048, F-33600 Pessac, France

Corresponding author: adelalalam@usek.edu.lb

Abstract:

The strong iconicity of $\mathrm{H}$ within rutile $\mathrm{MgH}_{2}$ is reduced by selective substitution of $\mathrm{Mg}$ by $T$ (= Fe, Co, Ni, Pd, Pt) using trirutile super-structure host $T \mathrm{Mg}_{2} \mathrm{H}_{6}$. These novel model systems, as computed in the quantum mechanical framework of density functional theory, showed a gradual decrease of the charges carried by $\mathrm{H}$ down to $-0.02 e$ improving the use of $\mathrm{MgH}_{2}$ for applications.

Keywords:

A. intermetallics. B. bonding. C. interstitial content. E. electronic structure calculation. 


\section{Introduction}

Hydrogen storage materials such as hydrides are leading candidates for clean energy in the future. Archetype hydride $\mathrm{MgH}_{2}$ has been studied intensively owing to its large gravimetric density $\sim 7.6$ wt.\%. However, its high thermodynamic stability prevents hydrogen absorption/desorption at mild conditions, whence the difficulty of its ad hoc use in applications. Experimental and theoretical efforts have culminated over decades to overcome the latter intricacy. The kinetics of hydrogenation were improved experimentally either by the addition of catalysts $[1,2,3]$ or by the introduction of nickel as an adjoined metal such as in $\mathrm{Mg}_{2} \mathrm{NiH}_{4}$ [4]. Recent theoretical investigations suggested the insertion of light elements such as carbon and boron which decreased the largely ionic character of hydrogen in $(B, C)_{0.167} \mathrm{MgH}_{2}$ [5].

The aim of the present study is to remedy the situation prohibiting the use of $\mathrm{MgH}_{2}$ in devices by selective substitution of $\mathrm{Mg}$ with transition metals ( $T=\mathrm{Fe}, \mathrm{Co}, \mathrm{Ni}, \mathrm{Pd}, \mathrm{Pt})$ in a trirutile host super-structure using first-principles density functional theory (DFT) calculations $[6,7]$.

\section{Structural details}

As illustrated in Fig. 1, ordered trirutile $\mathrm{TMg}_{2} \mathrm{H}_{6}$ crystallizes as rutile with the tetragonal structure in space group $P 4_{2} / m n m$ (No. 136). Given in Wyckoff letter, $T$ atoms occupy $2 a$ sites at coordinates $(0,0,0)$, and $\mathrm{Mg}$ atoms are found in $4 e$ sites at $(0,0, z \sim 1 / 3)$. There are two hydrogen sub-lattices, namely $\mathrm{H} 1$ at $4 f(x, x, 0)$ and $\mathrm{H} 2$ at $8 j(x, x, z)$. Both $\mathrm{Mg}$ and $T$ species are surrounded by irregular $\mathrm{H}$ octahedra. Successive $T$ - $\mathrm{H}$ planes (at $z=0$ and $z$ $=1 / 2$ ) are separated by two Mg-H planes (at $z \sim 1 / 6$ and $z \sim 1 / 3$ ).

Archetype $\mathrm{MgH}_{2}$ crystallizes with the tetragonal rutile structure in space group $P 4_{2} / m n m$ (No. 136). The latter order can be compared to the trirutile structure by substituting $T$ species by $\mathrm{Mg}$ at $2 a$ sites, whereby $\mathrm{H}$ atoms are located exclusively at $4 f$ sites.

\section{Computational methodology}

Geometry optimization and total energy calculations were performed with the Vienna ab initio simulation package (VASP) [8,9]. The ion-electron interactions were described using the projector augmented wave (PAW) method [9, 10]. Electron exchangecorrelation functionals were built within the generalized gradient approximation (GGA) 
scheme following the nonlocal correction of Perdew, Burke and Ernzerhof (PBE) [11]. It is important to mention that semi-core $p$ states where accounted for PAW potentials of $\mathrm{Mg}$ in order to obtain the correct physical bulk properties and electronic structures for $\mathrm{TMg}_{2} \mathrm{H}_{6}$ models. The conjugate-gradient algorithm [12] is used in this computational scheme to relax the atoms and to optimize the structural parameters until the forces on all the unconstrained atoms were less than $0.02 \mathrm{eV} / \AA$ and all stress components were less than $0.003 \mathrm{eV} / \AA^{3}$. The tetrahedron method with Blöchl corrections [10] and a Methfessel-Paxton [13] Gaussian smearing scheme were applied for both geometry relaxation and to accelerate the total energy calculations. Brillouin-zone (BZ) integrals were approximated using the special $k$-point sampling. The calculations are converged at an energy cut-off of $404 \mathrm{eV}$ for the plane-wave basis set with respect to the $k$-point integration with a starting mesh of $4 \times 4 \times 4$ up to $8 \times 8 \times 8$ for best convergence and relaxation to zero strains.

In this work, the atomic charge of hydrogen is calculated using a Bader charge analysis [14]. The latter approach partitions the continuous electron density into region bounded by the minima of the charge density. Such an analysis can be useful when trends between similar compounds are examined; it does not constitute a tool for evaluating absolute ionizations. Bader's analysis is done using a fast algorithm operating on a charge density grid [15]. The results of computed charges $Q$ are such that they lead to neutrality when the respective multiplicities are accounted for.

\section{Results and discussions}

\subsection{Geometry optimization, cohesive energies and hydrogen charge density}

In as far as $T \mathrm{Mg}_{2} \mathrm{H}_{6}$ models are novel theoretical models chosen herein, geometry optimization was firstly performed. Starting and optimized structural parameters are given in Table 1. Rutile-type $\mathrm{MgH}_{2}$ was also examined to establish trends of stability for the computed $T \mathrm{Mg}_{2} \mathrm{H}_{6}$ models. The calculated structural parameters for $\mathrm{MgH}_{2}$ are within $2 \%$ of the experiment. All $\mathrm{TMg}_{2} \mathrm{H}_{6}$ models relaxed in the trirutile structure. The stability of these models can be examined from the computed total electronic energies given in Table 2.

The cohesive energies of various $\mathrm{TMg}_{2} \mathrm{H}_{6}$ structures were calculated with the expression

$$
E_{\text {coh. }}=E\left(T_{2} \mathrm{Mg}_{4} \mathrm{H}_{12}\right)-2 E(T)-4 E(\mathrm{Mg})-6 E\left(\mathrm{H}_{2}\right)
$$


The energy terms on the right-hand side of the equation represent, in order, trirutile hydride model, pure $\mathrm{T}$ metal, pure $\mathrm{Mg}$, and gas-phase hydrogen. The strength of cohesive energy of a model is a measure of the stability of that model. Largely negative $E_{\text {coh. }}$ indicate stable binding, whereas positive energies correspond to an unstable model. The energy of the gas-phase hydrogen dimer was calculated with an $8 \times 8 \times 8$ cell. The cohesive energy per $\mathrm{H}_{2}$ of $\mathrm{MgH}_{2}$ is calculated within $8 \%$ of the experimental value $-0.79 \mathrm{eV}$ [17]. The computed $E_{\text {coh. }}$ per $\mathrm{H}_{2}$ values in Table 2 clearly indicate that all $T \mathrm{Mg}_{2} \mathrm{H}_{6}$ models are stable owing to the negative values. Compared to $\mathrm{MgH}_{2}$, all models are less stable. The latter finding meets with the aims of this study in as far as less thermodynamically stable hydrides are sought.

The latter should be comforted further by examining the atomic charge of hydrogen shown as a function of $T$ species in Fig. 2. As expected, hydrogen exhibits a less ionic character near $T$ elements (H1 sub-lattice) compared to $\mathrm{H}$ charges near Mg (H2 sublattice). This can be explained by the electronegativity value of the different species given in the Pauling scale: $\chi(\mathrm{Mg})=1.31, \chi(\mathrm{Fe})=1.83, \chi(\mathrm{Co})=1.88, \chi(\mathrm{Ni})=1.91, \chi(\mathrm{Pd})=$ 2.2 , and $\chi(\mathrm{Pt})=2.28$. All $T$ elements are more electronegative than $\mathrm{Mg}$, whence the less ionic hydrogen in their surroundings. Furthermore, $\mathrm{H} 1$ charge near $T$ elements undergoes gradual reduction of its ionic character from $\mathrm{H}^{-0.4}$ for $\mathrm{FeMg}_{2} \mathrm{H}_{6}$ model down to $\mathrm{H}^{-} 0.02$ for $\mathrm{PtMg}_{2} \mathrm{H}_{6}$. The latter value is also due to the large H1-Pt separation $d_{\mathrm{H} 1-\mathrm{Pt}}=$ $1.80 \AA$. The other hydrogen sub-lattice, namely $\mathrm{H} 2$, exhibits a constant evolution around a charge of $-6 e$. Nevertheless the overall changes brought by $T$ are established. This substantial reduction of the carried charge by $\mathrm{H}$ predicted theoretically should be an indication of the readiness of $\mathrm{H}$ desorption experimentally. It is important to mention that smaller amounts of metal would be needed to strongly modify $\mathrm{MgH}_{2}$ especially with platinum which is an expensive metal. Tests are underway with experimental groups at our Institute.

Further we comment on the relative changes of charges on $T$ using the Bader charge analysis. The values are as follows:

Fe+0.71; Co: +0.50 : Ni: +0.52: Pd: 0.27; Pt: +0.13 . The ionization degree follows closely the electronegativity magnitude with the following trend: the least electronegative is the least charged. 


\subsection{Electronic density of states: DOS analysis}

Fig. 3 shows the site projected density of states (PDOS) corresponding to $\mathrm{Mg}_{3} \mathrm{H}_{6}$ and $T \mathrm{Mg}_{2} \mathrm{H}_{6}$. The energy along the abscissa axis is brought to $E_{\mathrm{V}}$, top of the valence band (VB) which is separated from the conduction band (CB) by a band gap of $\sim 3.5 \mathrm{eV}$ for trirutile$\mathrm{Mg}_{3} \mathrm{H}_{6}$ (Figs. 3a and b). This agrees with the insulating character of archetype $\mathrm{MgH}_{2}$ showing a band gap of $\sim 5.6 \mathrm{eV}$ [18]. The $\mathrm{VB}$ is dominated by $\mathrm{H}(\mathrm{H} 1$ and $\mathrm{H} 2)$ with prevailing $\mathrm{H} 2$ intensities due to their higher multiplicity with respect to H1. Magnesium PDOS are dominating within the $\mathrm{CB}$ due to their low filling and electron departure towards $\mathrm{H}$.

The DOS's of $T \mathrm{Mg}_{2} \mathrm{H}_{6}$ show a few similar feature with $\mathrm{MgH}_{2}$-like DOS within the $8 \mathrm{eV}$ range from -2 to $-10 \mathrm{eV}$ (Figs. 3c,d,e). Similar DOS skylines are also observed within the CB between itinerant $T$ states and the $\mathrm{Mg} / \mathrm{H}$ states. The band gap has decreased down to $\sim 2.5 \mathrm{eV}$ for $\mathrm{Fe}$ due to the covalent character brought in by iron. From Co to $\mathrm{Ni}$ and $\mathrm{Pt}$ the extra electrons brought by the increasing $\mathrm{Z}$ number shifts $\mathrm{E}_{\mathrm{F}}$ to the states $\mathrm{Mg}$ and $\mathrm{H}$ formerly found within the CB. However the doping is far too high and leads to closing of the gap. A peculiar feature appears for the localized (sharp) $T \mathrm{n} d$-states PDOS which signals little mixing with the host $\mathrm{Mg}$ and $\mathrm{H}$ states and could be labeled as non bonding, as shown by the small PDOS magnitude of $\mathrm{Mg}$ and $\mathrm{H}$ below the $\mathrm{Fe}(d)$ PDOS for instance. The insulating character is preserved is as far as the energy is still referred the top of the VB but the gap is much reduced down to $\sim 0.3 \mathrm{eV}$. Clearly the amount of transition metal is too large $\left(\mathrm{FeMg}_{2} \mathrm{H}_{6} \equiv\right.$ $\mathrm{Fe}_{0.333} \mathrm{Mg}_{0.6667} \mathrm{H}_{2}$ ) by experimental standards. Note that some of the other transition elements candidates have shown total metallization, i.e. a closing of the band gap. Then smaller amounts of $T$ elements should be introduced in order to preserve the insulating properties of $\mathrm{MgH}_{2}$ and future works are planned. Nevertheless, our approach using trirutile host structure has shown relevant effects brought by $T$ substitution on the electronic structure of $\mathrm{MgH}_{2}$ owing to the use of trirutile super-structure allowing selective substitutions of $\mathrm{Mg}$.

\section{Conclusion}

The use of trirutile host super-structure allowed selective substitution of $\mathrm{Mg}$ by $T$ elements. This brought significant effects relevant to the reduction of the strong ionic character of $\mathrm{H}$ which prohibited the use of rutile $\mathrm{MgH}_{2}$ in applications. The introduction of $T$ species tends to narrow down the band gap of $\mathrm{MgH}_{2}$ leading to total metallization. Then smaller amounts 
should be introduced in order to preserve the insulating properties of $\mathrm{MgH}_{2}$ as future works are planned.

\section{Acknowledgement}

We acknowledge financial support from French-Lebanese CEDRE project and CSR-USEK. Part of the calculations where done on MCIA super computers of the University Bordeaux 1. Support from the Conseil Régional d'Aquitaine is gratefully acknowledged.

\section{References}

[1] D.W. Zhou, J.S. Liu, S.H. Xu, G.Y. Chen, Mater. Sci-Poland 28 (2010) 229.

[2] C.Z. Wu, P. Wang, X. Yao, C. Liu, D.M. Chen, G.Q. Lu, H.M.Cheng, J. Alloys Comp. 420 (2006) 278.

[3] M. Nakhl, M. Zakhour, Ch. Amine, H. El-Rassy, S.F. Matar, Adv. Mater. Res. 324 (2011) 119.

[4] J. Huot, J.F. Pelletier, G.Liang, M. Sutton, R. Schulz, J. Alloys Comp. 330-322 (2002) 727.

[5] S.F. Matar, Comp. Mater. Sci. 69 (2013) 424.

[6] P. Hohenberg, W. Kohn, Phys. Rev. B 136 (1964) 864.

[7] W. Kohn, L.J. Sham, Phys. Rev. A 140 (1965) 1133.

[8] G. Kresse, J. Furthmüller, Phys. Rev. B 54 (1996) 11169.

[9] G. Kresse, J. Joubert, Phys. Rev. B 59 (1999) 1758.

[10] P. E. Blöchl, Phys. Rev. B 50 (1994) 17953.

[11] J. Perdew, K. Burke, M. Ernzerhof, Phys. Rev. Lett. 77 (1996) 3865.

[12] W.H. Press, B.P. Flannery, S.A. Teukolsky, W.T. Vetterling, Numerical Recipes, Cambridge University Press, New York (1986). 
[13] M. Methfessel, A. T. Paxton, Phys. Rev. B 40 (1989) 3616.

[14] R. Bader Chem Rev 91 (1991) 893

[15] W. Tang, E. Sanville, G. Henkelman, J. Phys.: Condens. Matter, 21 (2009) 084204. http://theory.cm.utexas.edu/henkelman/research/bader

[16] P. Villars, L.D. Calvert, Peason's Handbook of Crystallographic Data for Intermetallic Phases, 2nd ed., American Society for Metals, Materials Park, OH, 1986.

[17] M. Yamaguchi, E. Akiba, Materials Science and technology,vol. 3B, VHC, New York, 1994, p. 333.

[18] C. Moysés Araújo, S. Lebègue, O. Eriksson, B. Arnaud, M. Alouani, R. Ahuja, J. Appl. Phys. 98 (2005) 096106. 
Table 1: Optimized and (starting experimental when available) structural parameters for $\mathrm{MgH}_{2}$ and $\mathrm{TMg}_{2} \mathrm{H}_{6}$ models. The distance separating $\mathrm{H} 1$ sublattice from $T$ element is also given.

\begin{tabular}{|c|c|c|c|c|c|c|}
\hline Structure & Unit C & ell (Å) & & Positi & nal para & neters \\
\hline & $A$ & $c / a$ & & $x$ & $Y$ & $Z$ \\
\hline $\mathrm{MgH}_{2}$ (rutile) & $\begin{array}{l}4.42 \\
(4.516)\end{array}$ & $\begin{array}{l}0.676 \\
(0.669)\end{array}$ & $\operatorname{Mg}(2 a)$ & $0(0)$ & $0(0)$ & $0(0)$ \\
\hline & & & $\mathrm{H}(4 f)$ & $\begin{array}{l}0.304 \\
(0.306)\end{array}$ & $\begin{array}{l}0.304 \\
(0.306)\end{array}$ & $0(0)$ \\
\hline $\mathrm{Mg}_{3} \mathrm{H}_{6}$ (trirutile) & 4.43 & 1.436 & $\operatorname{Mg}(4 e)$ & 0 & 0 & 0.333 \\
\hline & & & $\operatorname{Mg}(2 a)$ & 0 & 0 & 0 \\
\hline & & & $\mathrm{H} 1(4 f)$ & 0.304 & 0.304 & 0 \\
\hline & & & $\mathrm{H} 2(8 j)$ & 0.304 & 0.304 & 0.333 \\
\hline $\mathrm{FeMg}_{2} \mathrm{H}_{6}$ & 4.252 & 1.924 & $\operatorname{Mg}(4 e)$ & 0 & 0 & 0.329 \\
\hline & & & $\mathrm{Fe}(2 a)$ & 0 & 0 & 0 \\
\hline & & & $\mathrm{H} 1(4 f)$ & 0.267 & 0.267 & 0 \\
\hline$d_{\mathrm{H} 1-\mathrm{Fe}}=1.64 \AA$ & & & $\mathrm{H} 2(8 j)$ & 0.313 & 0.313 & 0.362 \\
\hline $\mathrm{CoMg}_{2} \mathrm{H}_{6}$ & 4.263 & 1.912 & $\operatorname{Mg}(4 e)$ & 0 & 0 & 0.328 \\
\hline & & & Co $(2 a)$ & 0 & 0 & 0 \\
\hline & & & $\mathrm{H} 1(4 f)$ & 0.266 & 0.266 & 0 \\
\hline$d_{\mathrm{H} 1-\mathrm{Co}}=1.64-1.66 \AA$ & & & $\mathrm{H} 2(8 j)$ & 0.313 & 0.313 & 0.364 \\
\hline $\mathrm{NiMg}_{2} \mathrm{H}_{6}$ & 4.262 & 2.002 & $\operatorname{Mg}(4 e)$ & 0 & 0 & 0.328 \\
\hline & & & $\mathrm{Ni}(2 a)$ & 0 & 0 & 0 \\
\hline & & & $\mathrm{H} 1(4 f)$ & 0.267 & 0.267 & 0 \\
\hline$d_{\mathrm{H} 1-\mathrm{Ni}}=1.54-1.61 \AA$ & & & $\mathrm{H} 2(8 j)$ & 0.312 & 0.312 & 0.360 \\
\hline $\mathrm{PdMg}_{2} \mathrm{H}_{6}$ & 4.351 & 2.032 & $\operatorname{Mg}(4 e)$ & 0 & 0 & 0.328 \\
\hline & & & Pd $(2 a)$ & 0 & 0 & 0 \\
\hline & & & $\mathrm{H} 1(4 f)$ & 0.280 & 0.280 & 0 \\
\hline$d_{\mathrm{H} 1-\mathrm{Pd}}=1.66-1.73 \AA$ & & & $\mathrm{H} 2(8 j)$ & 0.306 & 0.306 & 0.351 \\
\hline $\mathrm{PtMg}_{2} \mathrm{H}_{6}$ & 4.364 & 2.059 & $\operatorname{Mg}(4 e)$ & 0 & 0 & 0.327 \\
\hline & & & $\operatorname{Pt}(2 a)$ & 0 & 0 & 0 \\
\hline & & & $\mathrm{H} 1(4 f)$ & 0.277 & 0.273 & 0 \\
\hline$d_{\mathrm{H} 1-\mathrm{Pt}}=1.66-1.80 \AA$ & & & $\mathrm{H} 2(8 j)$ & 0.307 & 0.307 & 0.356 \\
\hline
\end{tabular}


Table 2: Total electronic energies and cohesive energies in units of eV for all $\mathrm{TMg}_{2} \mathrm{H}_{6}$ models.

\begin{tabular}{lllllll}
\hline Structure & $\boldsymbol{E}\left(\boldsymbol{T}_{\mathbf{2}} \mathbf{M g}_{\mathbf{4}} \mathbf{H}_{\mathbf{1 2}}\right)$ & $\boldsymbol{E}(\boldsymbol{T})$ & $\boldsymbol{E}(\mathbf{M g})$ & $\boldsymbol{E}\left(\mathbf{H}_{2}\right)$ & $\boldsymbol{E}_{\text {coh. }}$ & $\boldsymbol{E}_{\text {coh./H2 }}$ \\
\hline $\mathbf{M g H}_{\mathbf{2}}$ (rutile) & -17.570 & & -1.487 & -6.52 & -1.556 & -0.778 \\
\hline $\mathbf{F e M g} \mathbf{H}_{\mathbf{6}}$ & -64.517 & -7.813 & -1.487 & -6.52 & -3.823 & -0.637 \\
\hline $\mathbf{C o M g}_{2} \mathbf{H}_{\mathbf{6}}$ & -61.742 & -6.810 & -1.487 & -6.52 & -3.054 & -0.509 \\
\hline $\mathbf{N i M g}_{2} \mathbf{H}_{\mathbf{6}}$ & -57.907 & -5.725 & -1.487 & -6.52 & -1.389 & -0.232 \\
\hline $\mathbf{P d M g}_{\mathbf{2}} \mathbf{H}_{\mathbf{6}}$ & -56.832 & -5.360 & -1.487 & -6.52 & -1.044 & -0.174 \\
\hline $\mathbf{P t M g}_{\mathbf{2}} \mathbf{H}_{\mathbf{6}}$ & -59.140 & -5.366 & -1.487 & -6.52 & -3.340 & -0.557 \\
\hline
\end{tabular}
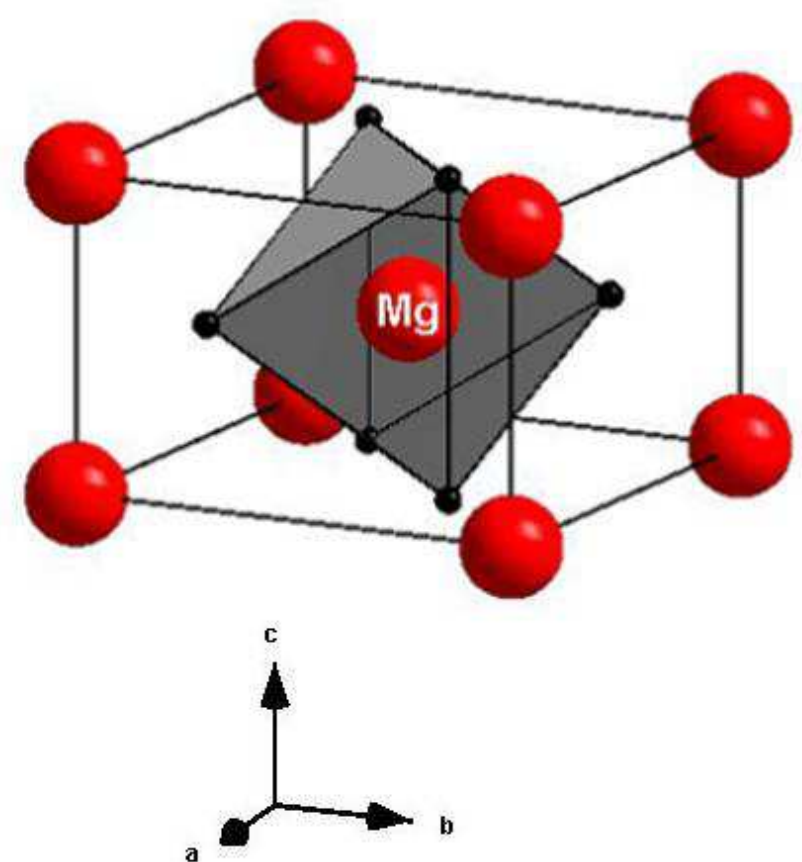

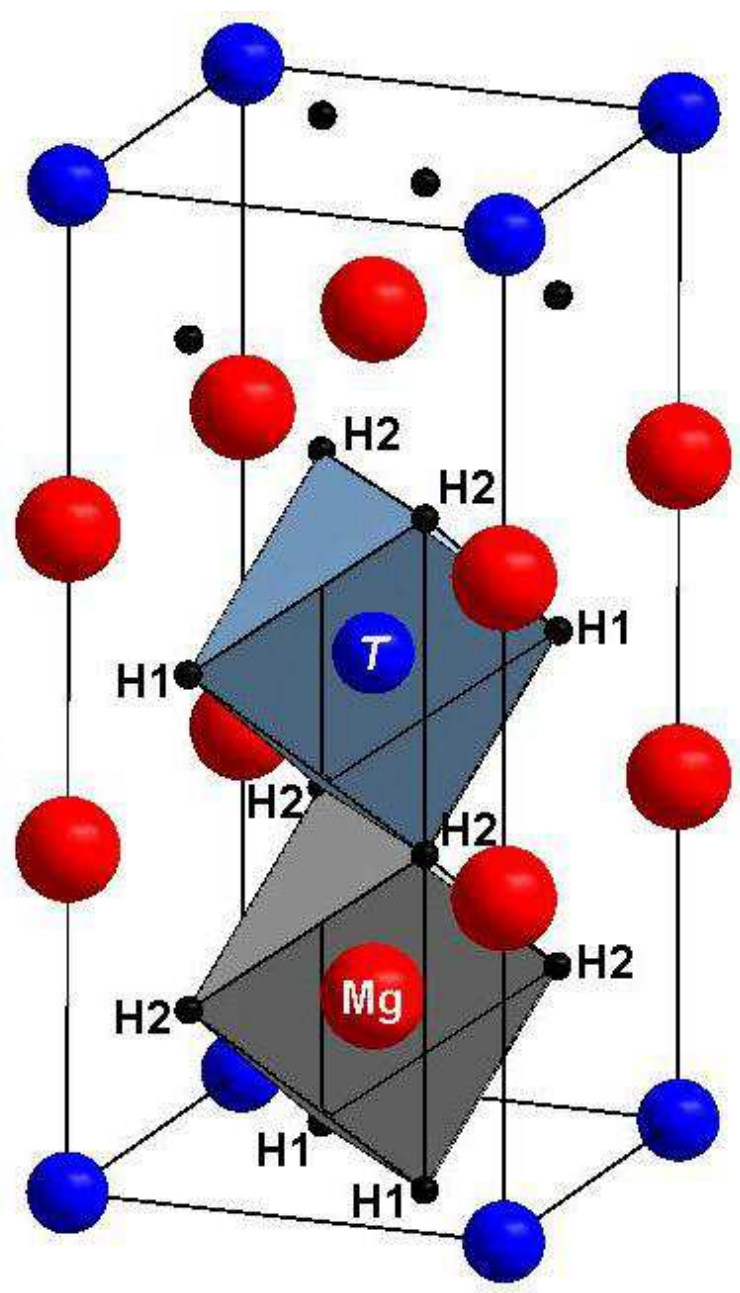

Fig. 1: (Color online) Sketches of the crystal structures of rutile-type $\mathrm{MgH}_{2}$ (left-hand side) and trirutile-type $\mathrm{TMg}_{2} \mathrm{H}_{6}$ (right-hand side). 


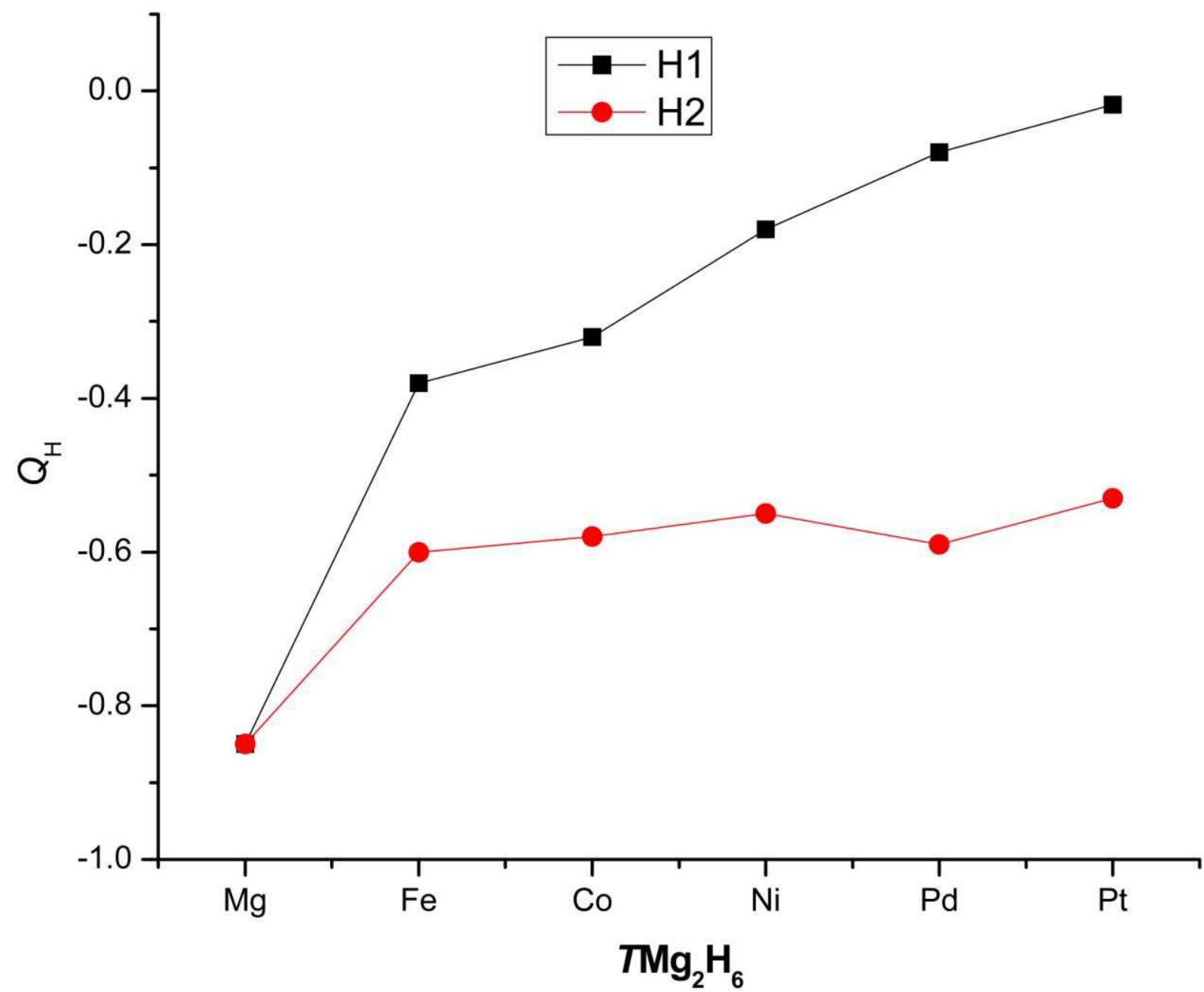

Fig. 2: (Color online) Atomic charge of hydrogen $Q_{\mathrm{H}}$ as function of $T$ species in all $T \mathrm{Mg}_{2} \mathrm{H}_{6}$ models for $\mathrm{H} 1$ and $\mathrm{H} 2$ sub-lattices. All values of $Q_{\mathrm{H}}$ are given as a multiple of elementary charge $\left(e=1.6 \times 10^{-19} \mathrm{C}\right)$. 


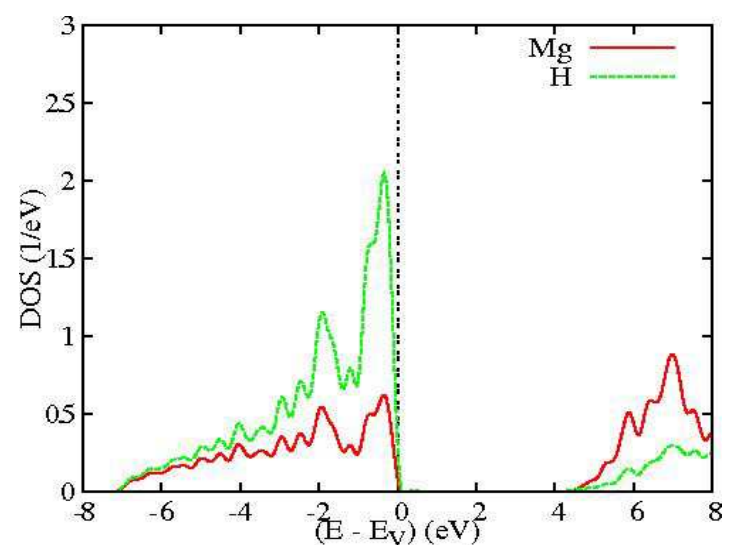

(a)

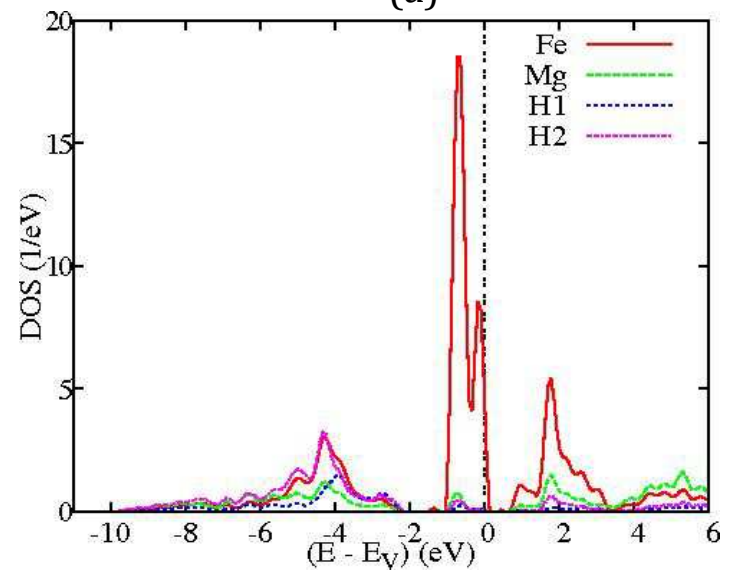

(c)

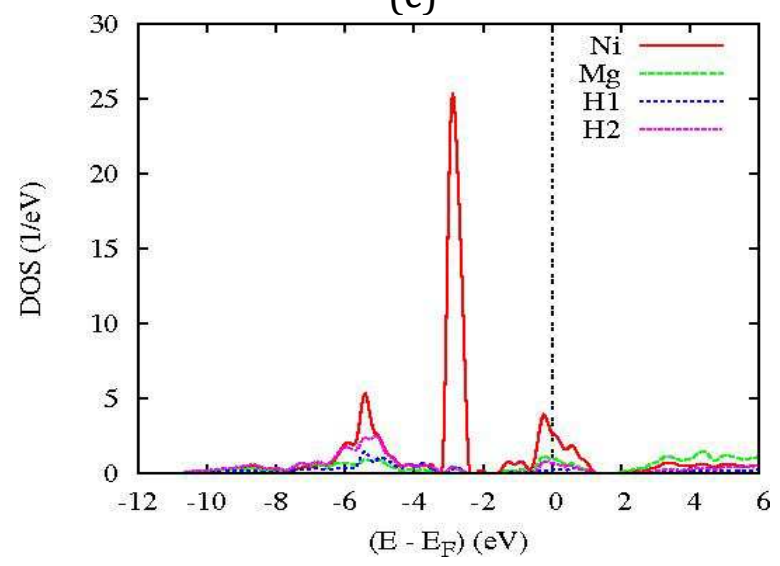

(e)

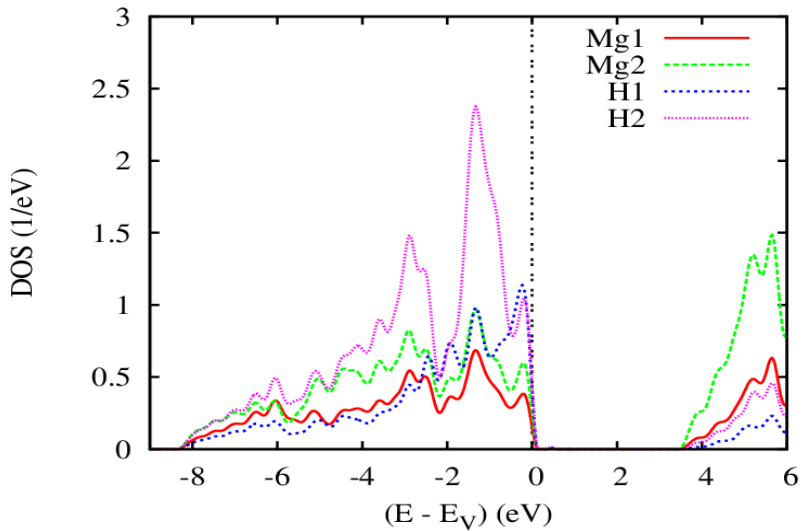

(b)

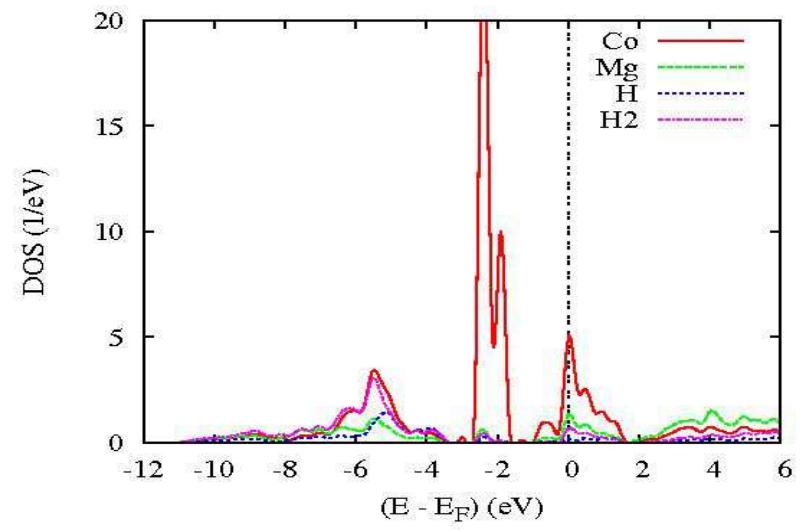

(d)

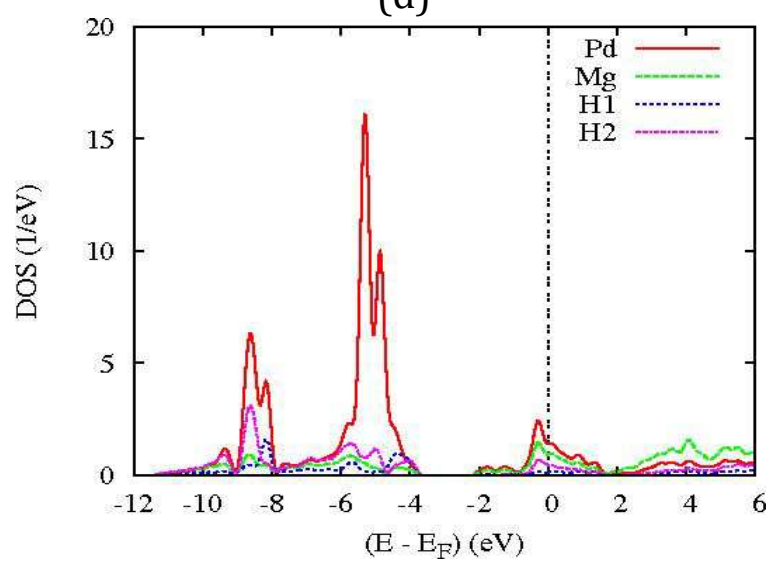

(f)

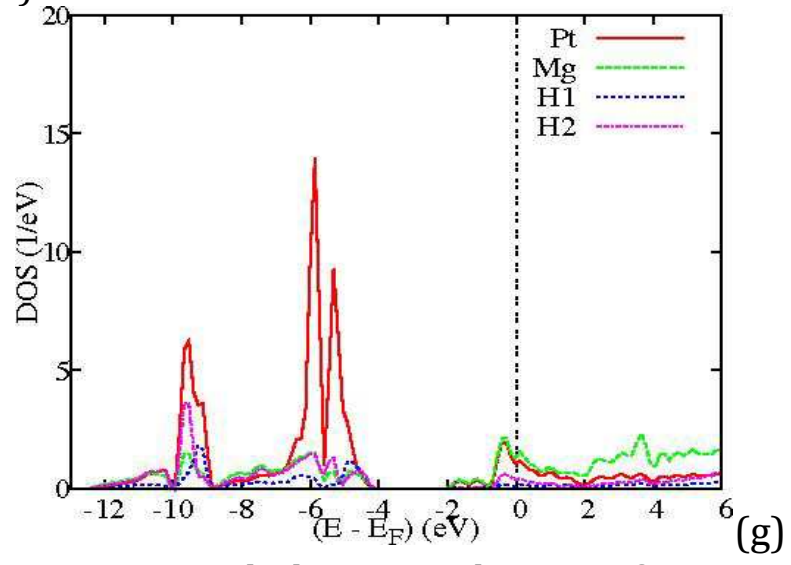

Fig. 3: (Color online) Site projected electronic density of states of: (a) rutile- $\mathrm{MgH}_{2}$, (b) trirutile- $\mathrm{Mg}_{3} \mathrm{H}_{6}$, (c) $\mathrm{FeMg}_{2} \mathrm{H}_{6}$, (d) $\mathrm{CoMg}_{2} \mathrm{H}_{6}$, (e) $\mathrm{NiMg}_{2} \mathrm{H}_{6}$, (f) $\mathrm{PdMg}_{2} \mathrm{H}_{6}$, (g) $\mathrm{PtMg}_{2} \mathrm{H}_{6}$. 